\title{
Identification of key biomarkers and potential molecular mechanisms in lung cancer by bioinformatics analysis
}

\author{
ZHENHUA LI ${ }^{1}$, MEIXIANG SANG ${ }^{2}$, ZIQIANG TIAN ${ }^{1}$, ZHAO LIU $^{3}$, JIAN LV $^{4}$, FAN ZHANG $^{1}$ and BAOEN SHAN ${ }^{2}$ \\ ${ }^{1}$ Department of Thoracic Surgery, The Fourth Affiliated Hospital of Hebei Medical University; ${ }^{2}$ Hebei Cancer Research \\ Center, The Fourth Affiliated Hospital of Hebei Medical University, Shijiazhuang, Hebei 050000; ${ }^{3}$ Department of \\ Gastrointestinal Surgery, Peking University Cancer Hospital, Beijing 100142; ${ }^{4}$ Second Department of Surgery, \\ The Fourth Affiliated Hospital of Hebei Medical University, Shijiazhuang, Hebei 050000, P.R. China
}

Received September 22, 2018; Accepted June 6, 2019

DOI: $10.3892 / \mathrm{ol} .2019 .10796$

\begin{abstract}
Lung cancer is one of the most widespread neoplasms worldwide. To identify the key biomarkers in its carcinogenesis and development, the mRNA microarray datasets GSE102287, GSE89047, GSE67061 and GSE74706 were obtained from the Gene Expression Omnibus database. GEO2R was used to identify the differentially expressed genes (DEGs) in lung cancer. The Database for Annotation, Visualization and Integrated Discovery was used to analyze the functions and pathways of the DEGs, while the Search Tool for the Retrieval of Interacting Genes/Proteins and Cytoscape were used to obtain the protein-protein interaction (PPI) network. Kaplan Meier curves were used to analyze the effect of the hub genes on overall survival (OS). Module analysis was completed using Molecular Complex Detection in Cytoscape, and one co-expression network of these significant genes was obtained with cBioPortal. A total of 552 DEGs were identified among the four microarray datasets, which were mainly enriched in 'cell proliferation', 'cell growth', 'cell division', 'angiogenesis' and 'mitotic nuclear division'. A PPI network, composed of 44 nodes and 886 edges, was constructed, and its significant module had 16 hub genes in the whole network: Opa interacting protein 5, exonuclease 1, PCNA clamp-associated factor, checkpoint kinase 1,
\end{abstract}

Correspondence to: Dr Baoen Shan, Hebei Cancer Research Center, The Fourth Affiliated Hospital of Hebei Medical University, 14 Jiankang Road, Shijiazhuang, Hebei 050000, P.R. China E-mail: baoenshan@163.com

Abbreviations: DEGs, differentially expressed genes; PPI, protein-protein interaction; GO, Gene Ontology; KEGG, Kyoto Encyclopedia of Genes and Genomes; GEO, Gene Expression Omnibus; DAVID, Database for Annotation, Visualization and Integrated Discovery

Key words: lung cancer, bioinformatics analysis, differentially expressed genes, Gene Ontology and Kyoto Encyclopedia of Genes and Genomes enrichment analysis, protein-protein interaction, survival analysis hyaluronan-mediated motility receptor, maternal embryonic leucine zipper kinase, non-SMC condensin I complex subunit G, centromere protein F, BUB1 mitotic checkpoint serine/threonine kinase, cyclin A2, thyroid hormone receptor interactor 13, TPX2 microtubule nucleation factor, nucleolar and spindle associated protein 1 , kinesin family member 20A, aurora kinase A and centrosomal protein 55. Survival analysis of these hub genes revealed that they were markedly associated with poor OS in patients with lung cancer. In summary, the hub genes and DEGs delineated in the research may aid the identification of potential targets for diagnostic and therapeutic strategies in lung cancer.

\section{Introduction}

Lung cancer, one of the most common malignant tumors, is the leading cause of cancer-associated morbidity in the population worldwide; it is the most common cancer among males and the fourth most common tumor in women (1). Lung cancer is divided into different pathological subtypes, including adenocarcinoma, squamous cell carcinoma and small cell lung cancer (SCLC) (1). The occurrence, development and metastasis of lung cancer include a number of orchestrated steps, including DNA mutations and injury (2). Despite an increased understanding of the underlying molecular mechanisms of the disease and the implementation of novel therapeutic strategies, the 5-year survival rate remains low. The study of the molecular mechanism of cancer guides the classification and treatment of lung cancer, and promotes the rapid progress of targeted therapy and immunotherapy. The large-scale research and clinical trials of these new therapies provide prospects for the individualized treatment of lung cancer.

Much progress has been made with lung cancer biomarkers over the last decade, and biomarkers have been widely applied in the diagnosis, treatment and prognosis evaluation of lung cancer, with further biomarkers now being studied. For example, anaplastic lymphoma kinase (ALK) was initially identified to be abnormally downregulated in lung cancer and a fusion of echinoderm microtubule-associated protein-like 4 (EML4) and ALK genes was found in $3.7-7 \%$ of non-SCLC (NSCLC) (3). Due to ALK fusion, 57-74\% of patients with lung adenocarcinoma respond well to ALK inhibitors such 
as crizotinib (3). The study revealed that the median progression-free survival (PFS) and response rates of patients who received crizotinib were significantly improved compared with those of patients treated with chemotherapy (4). The epidermal growth factor receptor (EGFR), a tyrosine kinase receptor, was overexpressed in $62 \%$ of patients with NSCLC (5). Tyrosine kinase inhibitors have been the standard treatment of patients with EGFR mutations due to their high response rate (55-78\%) and PFS rate (1). Therefore, the discovery of new diagnostic and therapeutic targets is of great significance for the early diagnosis, drug development and targeted therapy of lung cancer.

Bioinformatics analysis has been commonly applied in cancer research to identify genetic changes associated with cancer. Previous studies have performed bioinformatics analysis to identify differentially expressed genes (DEGs) in various types of cancer, as well as to determine their roles in biological processes, molecular functions and different pathways $(6,7)$. Accordingly, the present study analyzed data generated by microarray technology to explore the potential pathogenesis of lung cancer. Specifically, given the high number false-positives associated with the analysis of a single microarray, four public mRNA datasets were screened in the present study to identify DEGs between lung cancer and adjacent non-cancerous tissue samples. Subsequently, Gene Ontology (GO) and Kyoto Encyclopedia of Genes and Genomes (KEGG) analyses were performed, and a protein-protein interaction (PPI) network analysis was used to assist in demonstrating the molecular pathogenesis underlying the carcinogenesis and development of lung cancer. A total of 552 DEGs and 16 hub genes were identified and they may serve as candidate biomarkers in lung cancer.

\section{Materials and methods}

Public mRNA datasets. Gene Expression Omnibus (GEO; www.ncbi.nlm.nih.gov/geo) is an open platform to store genetic data (8). Four gene expression profiles (GSE102287, GSE89047, GSE67061 and GSE74706) were acquired from the GEO The GSE102287 dataset contained 32 cancer samples and 34 normal samples (9). The GSE89047 dataset consisted of 8 cancer samples and 8 normal samples. The GSE67061 contained 56 cancer samples and 17 normal samples. The GSE74706 contained 18 cancer samples and 18 normal samples (10). The datasets consisted of a number of pathological subtypes of lung cancer, including NSCLC and lung squamous cell carcinoma. In the current study, in order to be more representative, a specific pathological type was not specified when selecting datasets.

Identification of DEGs. GEO2R (www.ncbi.nlm.nih. gov/geo/geo2r) is an interactive online tool to identify DEGs from GEO series (11). GEO2R was applied to distinguish DEGs between normal and lung cancer tissue samples. Duplicate and absent probe sets were removed. The cut-off criteria for the identification of DEGs were $\log _{2}$ fold-changel $>1$ and adjusted $\mathrm{P}<0.05$.

Functional annotation for DEGs with KEGG and GO analysis. The Database for Annotation, Visualization and Integrated Discovery (DAVID; www.david.abcc.ncifcrf.gov) provides typical batch annotation and GO (www.geneontology.org) analysis to highlight the most relevant GO terms associated with a given gene list (12). GO covers three aspects of biology, including biological process, molecular function and cellular component. KEGG (version 90.0; www.kegg.jp), is one of the most commonly used biological information databases in the world (13). Following KEGG and GO analysis in DAVID, functional annotation for DEGs was performed. $\mathrm{P}<0.05$ was considered to indicate a statistically significant difference.

Construction of the PPI network and identification of a significant module. The Search Tool for the Retrieval of Interacting Genes (version 11.0; string.embl.de) (14), an online open tool, was applied to construct a PPI network, and Cytoscape (version 3.7.1) (15) was used to present the network. Using a confidence cutoff of $>0.4$, a node score cutoff of 0.2 , a degree cutoff of 10 , a maximum depth of 100 and a k-core of 2 , the significant modules in the aforementioned PPI network were identified using the Molecular Complex Detection tool (version 1.5.1) (16). Subsequently, functional annotation for the genes in this module were performed using KEGG and GO analysis in DAVID.

Analysis and identification of hub genes. Hub genes with $\geq 43$ degrees were selected. cBioPortal (www.cbioportal.org) integrates The Cancer Genome Atlas (TCGA; portal.gdc. cancer.gov), the International Cancer Genome Consortium (icgc.org) and other cancer genome database data to provide online visualization tools. Based on the hub genes screened, a gene co-expression network was constructed and cBioportal was used to search for genes with a similar expression pattern to the hub genes in lung cancer and to investigate the interaction between genes (17). Furthermore, hub genes were analyzed with the biological process analysis, and were visualized using the BiNGO tool in Cytoscape (version 3.7.1) (18). The Kaplan-Meier plotter (kmplot.com/analysis) and the log rank test were used to plot and compared survival curves, respectively. The Kaplan-Meier plotter is an online tool that integrates gene expression data and clinical data from TCGA, GEO and the European Genome-Phenome Archive databases (www.ebi. ac.uk/ega/home). According to the different quantile expression levels of the proposed biomarkers, patients were divided into two groups to analyze the prognostic value of specific genes (19).

\section{Results}

Screening of DEGs in lung cancer. The analysis of the GSE67061, GSE74706, GSE89047 and GSE102287 datasets revealed 5,553, 5,562, 4,028 and 4,703 DEGs, respectively (Fig. 1A). Venn diagram analysis revealed that 552 DEGs (389 downregulated and 163 upregulated genes) were present in the four datasets (Fig. 1B; Table SI).

Functional annotation for DEGs using KEGG and GO analysis. The results of GO analysis revealed that the biological processes were primarily enriched in 'cell proliferation', 'cell growth', 'cell division', 'cell adhesion', 'angiogenesis', 'mitotic nuclear division', 'mitotic cytokinesis', 'leukocyte migration', 'GTPase activity' and 'epithelial cell proliferation'. Variations in molecular function were enriched in 'calcium ion binding', 
A
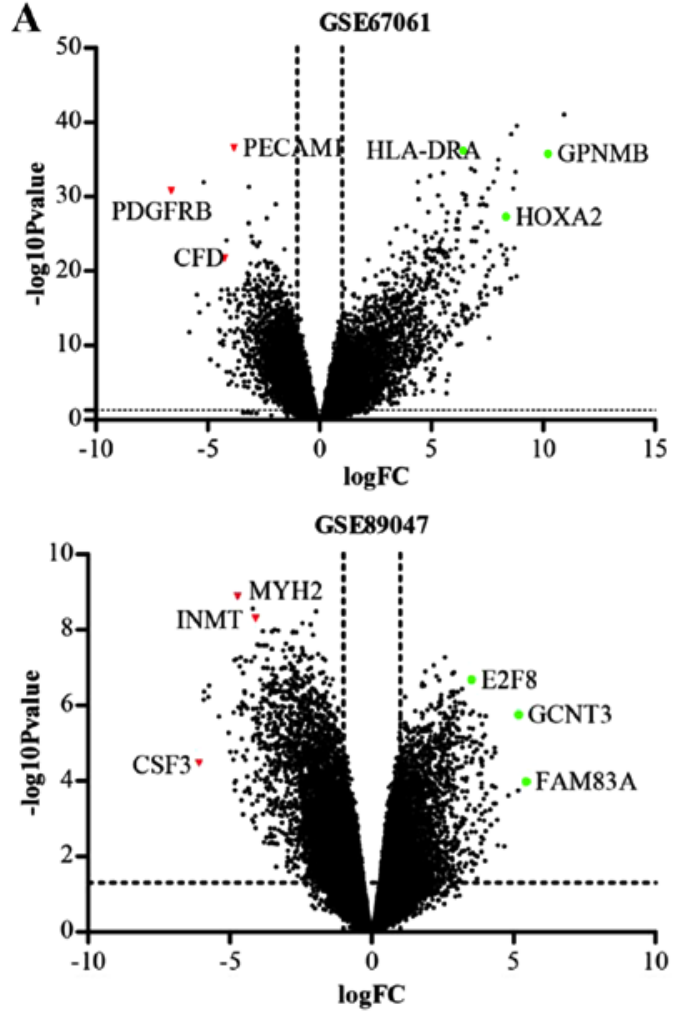

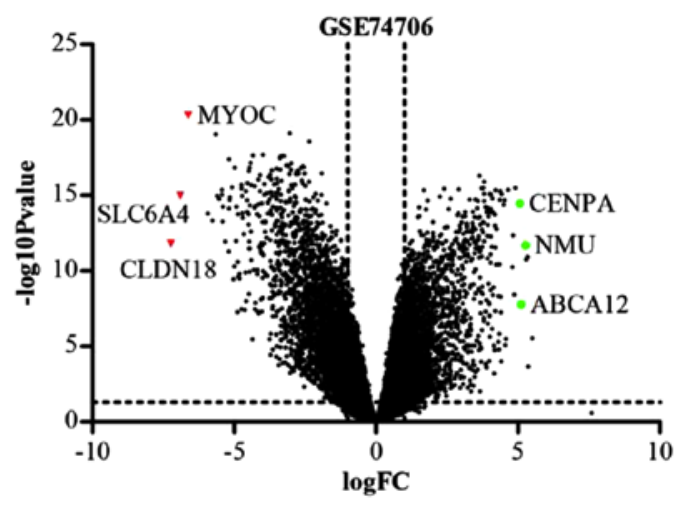

GSE102287

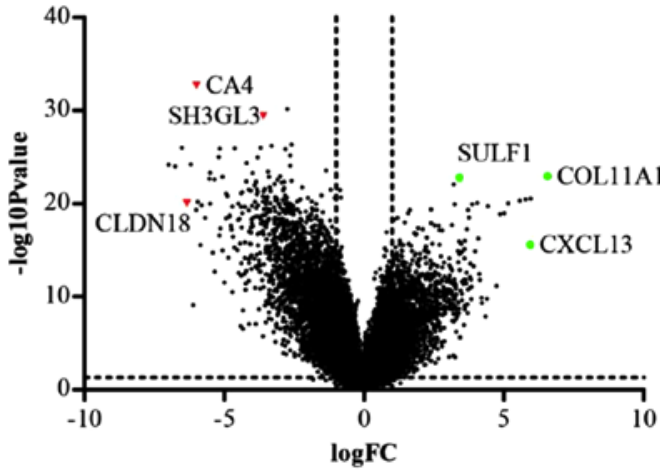

GSE102287

B

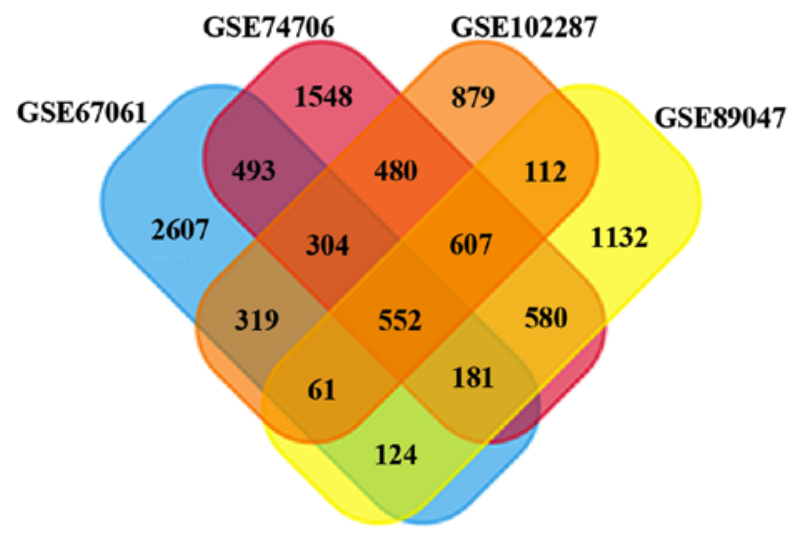

Figure 1. Volcano plots and Venn diagram. (A) Differentially expressed genes were selected with $\mid \log 2$ fold changel $>1$ and adjusted P $<0.05$ among the mRNA expression profiling datasets GSE102287, GSE67061, GSE89047 and GSE74706. The red triangles represent downregulated genes and the green circles represent upregulated genes. (B) A total of 552 intersecting genes were identified in the four datasets. FC, fold-change.

'heparin binding', 'PDZ domain binding', 'integrin binding', 'GTPase activator activity', 'growth factor binding', 'collagen binding', 'carbohydrate binding', 'scavenger receptor activity' and 'protein kinase binding'. Changes in cellular component were mainly enriched in 'extracellular matrix', 'extracellular region', 'extracellular space', 'sarcolemma', 'cell cortex', 'spindle pole', 'midbody', 'microtubule cytoskeleton', 'spindle' and 'collagen trimer'. KEGG pathway analysis revealed that DEGs were mainly enriched in 'cell cycle', 'oocyte meiosis', 'hypertrophic cardiomyopathy', 'vascular smooth muscle contraction', 'dilated cardiomyopathy', 'pathways in cancer', 'cell adhesion molecules', 'fanconi anemia pathway', 'renin-angiotensin system' and 'leukocyte transendothelial migration' (Fig. 2).

Construction of the PPI network and identification of a significant module. A PPI network was constructed and a significant module with 44 nodes and 886 edges was identified
(Fig. 3; Table SII). KEGG pathway and GO analysis of the DEGs involved in this module were analyzed using DAVID. Results revealed that genes in this module were significantly enriched in 'cell division', 'cell cycle' and 'mitotic nuclear division’ (Table I).

Hub gene selection and analysis. Hub genes with $\geq 43$ degrees were selected and a total of 16 genes were identified as previously described (20): Opa interacting protein 5 (OIP5), exonuclease 1 (EXO1), PCNA clamp-associated factor (KIAA0101), checkpoint kinase 1 (CHEK1), hyaluronan-mediated motility receptor (HMMR), maternal embryonic leucine zipper kinase (MELK), non-SMC condensin I complex subunit $\mathrm{G}$ (NCAPG), centromere protein $\mathrm{F}$ (CENPF), BUB1 mitotic checkpoint serine/threonine kinase (BUB1), cyclin A2 (CCNA2), thyroid hormone receptor interactor 13 (TRIP13), TPX2 microtubule nucleation factor (TPX2), nucleolar and 


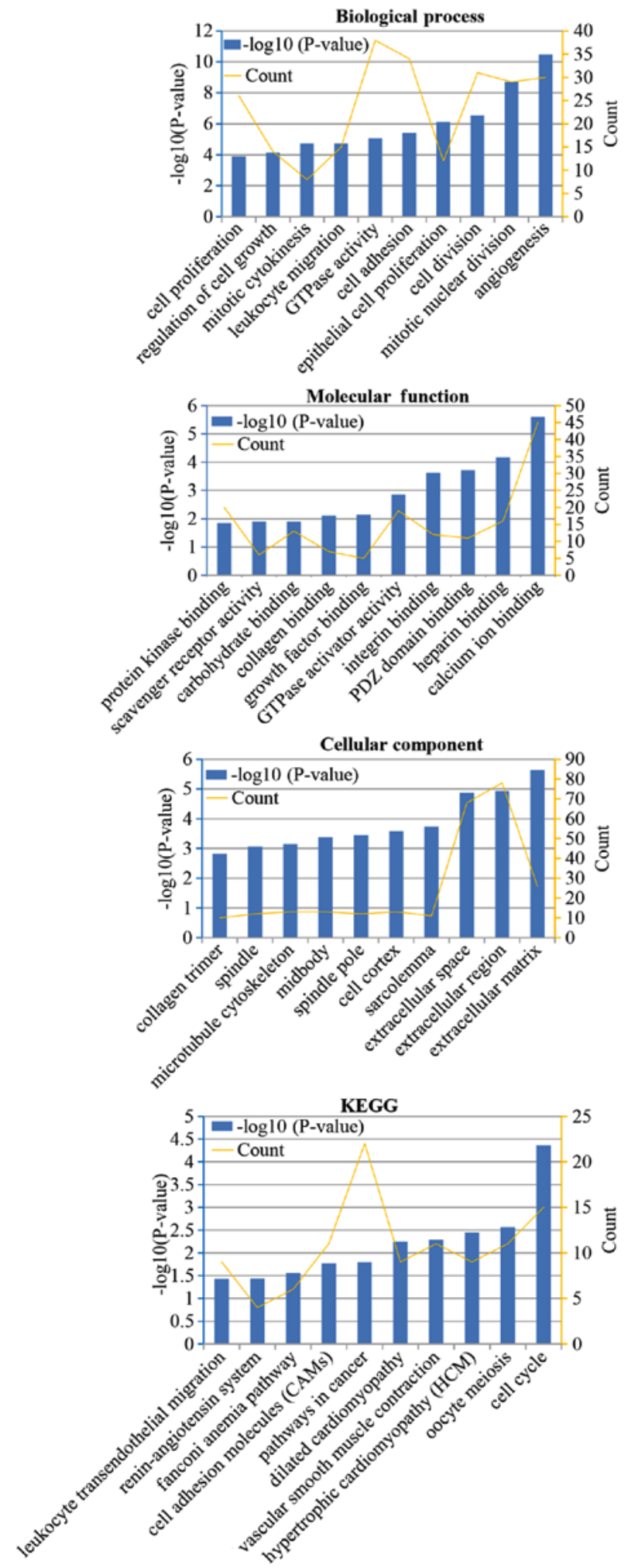

Figure 2. Functional and pathway enrichment analysis of differentially expressed genes in lung cancer.

spindle associated protein 1 (NUSAP1), kinesin family member 20A (KIF20A), aurora kinase A (AURKA) and centrosomal protein 55 (CEP55; Table II). A co-expression network of these genes was obtained using cBioPortal (Fig. 4). The biological process analysis for these genes is presented in Fig. 5. Kaplan-Meier survival curves were used to perform the overall survival analysis. Patients with lung cancer with a high expression level of OIP5, EXO1, KIAA0101, CHEK1, HMMR, MELK, NCAPG, CENPF, BUB1, CCNA2, TRIP13, TPX2, NUSAP1, KIF20A, AURKA and CEP55 exhibited a worse 5 -year overall survival time compared with patients with low expression (Figs. 6 and 7).

\section{Discussion}

Lung cancer is one of the most common malignancies worldwide, both in terms of incidence and mortality $(21,22)$. Despite significant advances in diagnostic and treatment strategies, the prognosis of patients with lung cancer remains unsatisfactory. Therefore, there is a requirement for the identification of lung cancer biomarkers to serve as novel diagnostic and therapeutic targets. Bioinformatics analysis has been widely applied to investigate genetic alterations in the progression of diseases, and may enable the identification of novel therapeutic targets.

Previous studies have screened biomarkers associated with the different pathological subtypes of lung cancer (23-26). Similarly, the present study screened potential biomarkers of lung cancer. However, the present study differs from the previous literature in a number of ways. In the current study, research data was derived from different datasets, which allows diversification of data results. Four datasets were selected to reduce the errors associated with a single dataset and differences of sequencing platforms, so as to improve the credibility of the results. The aim of the present study was to screen common biomarkers and drug targets in various pathological types of lung cancer using bioinformatics analysis. Finally, different results were achieved due to the different data sources and statistical methods used. However, certain biomarkers identified in the current study are consistent with previously published studies (27-31).

In the present study, 552 common DEGs were identified in the four microarray datasets. GO enrichment analysis revealed that changes in the most significant module were mainly enriched in 'cell division', 'mitotic nuclear division' and ' $\mathrm{G}_{2} / \mathrm{M}$ transition of mitotic cell cycle', while changes in KEGG analysis were mainly enriched in the 'cell cycle' and 'p53 signaling pathway'. Previous studies demonstrated that dysregulation of the cell cycle is associated with carcinogenesis and the progression of tumors $(32,33)$. In the current study, a PPI network consisting of 44 nodes and 886 edges was constructed. The 16 genes with the highest degrees in the PPI network included OIP5, EXO1, KIAA0101, CHEK1, HMMR, MELK, NCAPG, CENPF, BUB1, CCNA2, TRIP13, TPX2, NUSAP1, KIF20A, AURKA and CEP55. Subsequently, survival analysis of these genes revealed that they were significantly associated with a worse 5-year overall survival time of patients with lung cancer.

The mechanism of lung cancer is driven by specific genetic and epigenetic changes (34). In certain types of cancer, such as gastric colorectal cancer, the expression of OIP5 is upregulated and may be associated with the occurrence of cancer $(35,36)$. However, its function in lung cancer remains unknown. EXO1 is a nuclease that modulates DNA recombination, maintains genomic stability and mediates cell cycle arrest. Several reports have indicated that functional polymorphisms of EXO1 may be associated with the occurrence of lung cancer, and it may serve as a novel biomarker for the diagnosis and 


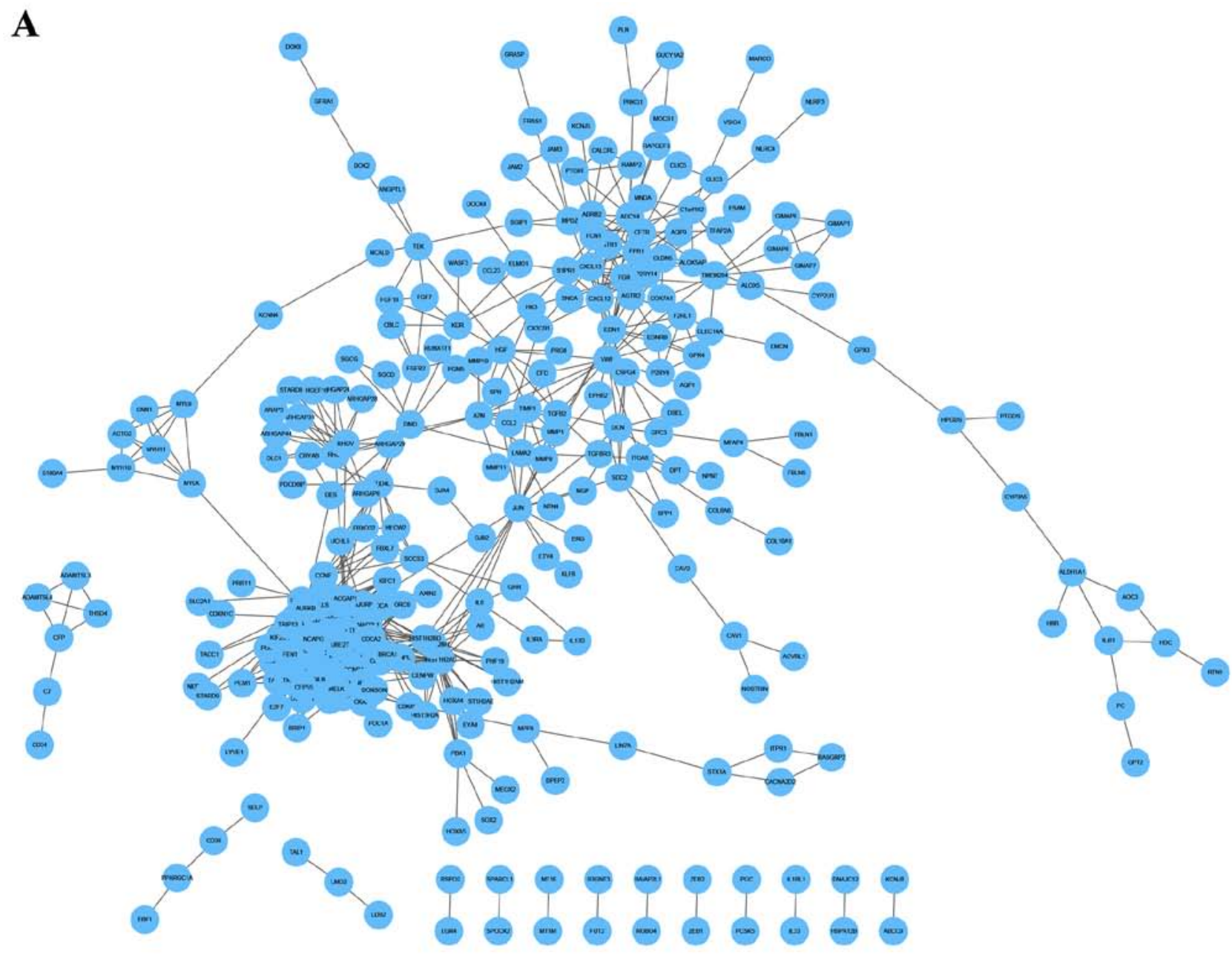

B

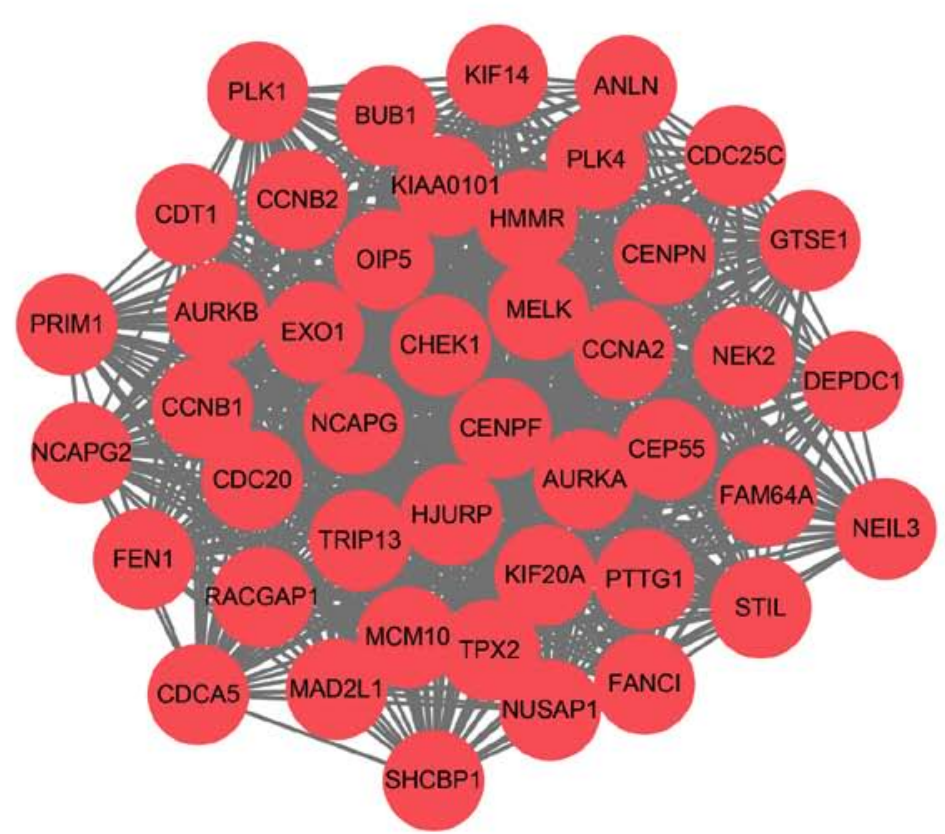

Figure 3. Construction of the PPI network and identification of a significant module. (A) The PPI network was constructed using Cytoscape. (B) The most significant module was obtained from the PPI network using Molecular Complex Detection, and included 44 nodes and 886 edges. PPI, protein-protein interaction.

treatment of lung cancer $(37,38)$. KIAA0101 is involved in cell cycle regulation and DNA repair and is expressed at high levels in several types of cancer, including gastric and lung cancer $(27,39,40)$. Previous studies reported that high expression levels of KIAA0101 and CHEK1 in lung cancer are associated with a poor prognosis $(27,41)$. 
Table I. GO and KEGG pathway enrichment analysis of the differentially expressed genes in the most significant module.

\begin{tabular}{llrr}
\hline Category & \multicolumn{1}{c}{ Term } & Count in gene set & P-value \\
\hline GOTERM_BP & Mitotic nuclear division & 19 & $<0.001$ \\
GOTERM_BP & Cell division & 18 & $<0.001$ \\
GOTERM_BP & G $/$ M transition of mitotic cell cycle & 11 & $<0.001$ \\
GOTERM_BP & Mitotic cytokinesis & 5 & $<0.001$ \\
GOTERM_MF & Protein binding & 39 & $<0.001$ \\
GOTERM_MF & Protein serine/threonine kinase activity & 8 & $<0.001$ \\
GOTERM_MF & Protein kinase binding & 8 & $<0.001$ \\
GOTERM_CC & Nucleoplasm & 29 & $<0.001$ \\
GOTERM_CC & Spindle & 9 & $<0.001$ \\
GOTERM_CC & Midbody & 9 & $<0.001$ \\
KEGG_PATHWAY & Cell cycle & 10 & $<0.001$ \\
KEGG_PATHWAY & p53 signaling pathway & 4 & $<0.001$ \\
KEGG_PATHWAY & FoxO signaling pathway & 4 & 0.006
\end{tabular}

GO, Gene Ontology; KEGG, Kyoto Encyclopedia of Genes and Genomes; BP, biological process; MF, molecular function; CC, cellular component

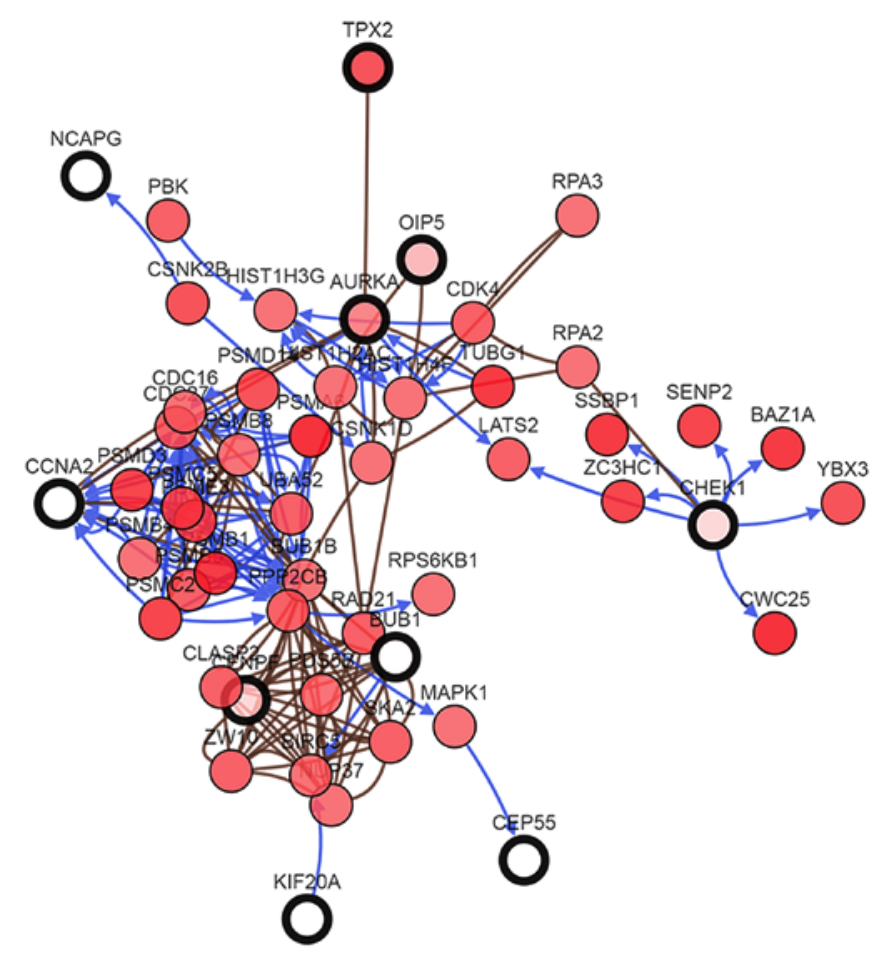

Figure 4. Hub genes and their co-expression genes were analyzed using cBioPortal. Nodes with a bold black outline represent hub genes. Red nodes with a thin black outline represent the co-expression genes. Blue arrows point to potential downstream targets of genes.

Man et al (28) revealed that HMMR, the receptor for hyaluronic acid, was upregulated in lung adenocarcinoma samples compared with healthy adjacent non-cancerous tissues. MELK is expressed in several types of human cancer $(42,43)$, including SCLC. Inoue et al (42) reported that inhibition of MELK may be a therapeutic strategy for SCLC. Zhang et al (44) reported that NCAPG may be implicated in hepatocellular carcinoma cell proliferation and migration, and may provide a promising novel therapeutic target for the treatment of advanced hepatocellular carcinoma. However, the clinical significance of NCAPG in lung cancer remains unknown.

Previous studies reported that CENPF serves a role in the tumorigenesis of hepatocellular carcinoma and prostate cancer $(45,46)$; however, its role in lung cancer requires further investigation. A number of studies demonstrated that BUB1 serves important roles in breast and endometrial cancer (47-49). However, Haruki et al (47-49) reported that the BUB gene family members, including BUB1, are not commonly associated with mitotic checkpoint defects in lung cancer. The potential association between BUB1 and lung cancer requires further investigation. Kim et al (29) reported that a functional single nucleotide polymorphism in the promoter region of CCNA2 was associated with an increased risk of lung cancer. TRIP13 is an ATPase that serves a key role in mitotic checkpoint complex inactivation and is associated with the progression of lung adenocarcinoma (30). Li et al (30) demonstrated that increased TRIP13 expression promoted lung adenocarcinoma progression and may serve as a potential therapeutic target or biomarker for the disease.

Yang et al $(50,51)$ revealed that TPX2 was associated with lung squamous carcinoma cell radioresistance and may serve as a therapeutic target to enhance cell radiosensitivity in lung squamous carcinoma. Furthermore, Schneider et al $(50,51)$ demonstrated that the expression of the TPX2, mitosis-associated gene, was associated with the prognosis of patients with NSCLC. Previous studies reported that overexpression of NUSAP1 was associated with a poor prognosis in prostate cancer, hepatocellular and oral squamous cell carcinoma $(52,53)$; however; little is known about the association of NUSAP1 with lung cancer. Zhao et al (54) demonstrated that KIF20A may confer a malignant phenotype in lung adenocarcinoma by regulating cell proliferation and apoptosis. AURKA, an oncogene, encodes a serine-threonine kinase that regulates mitotic processes in mammalian cells and serves as a potential therapeutic target of NSCLC $(55,56)$. Lo et al $(55,56)$ reported 


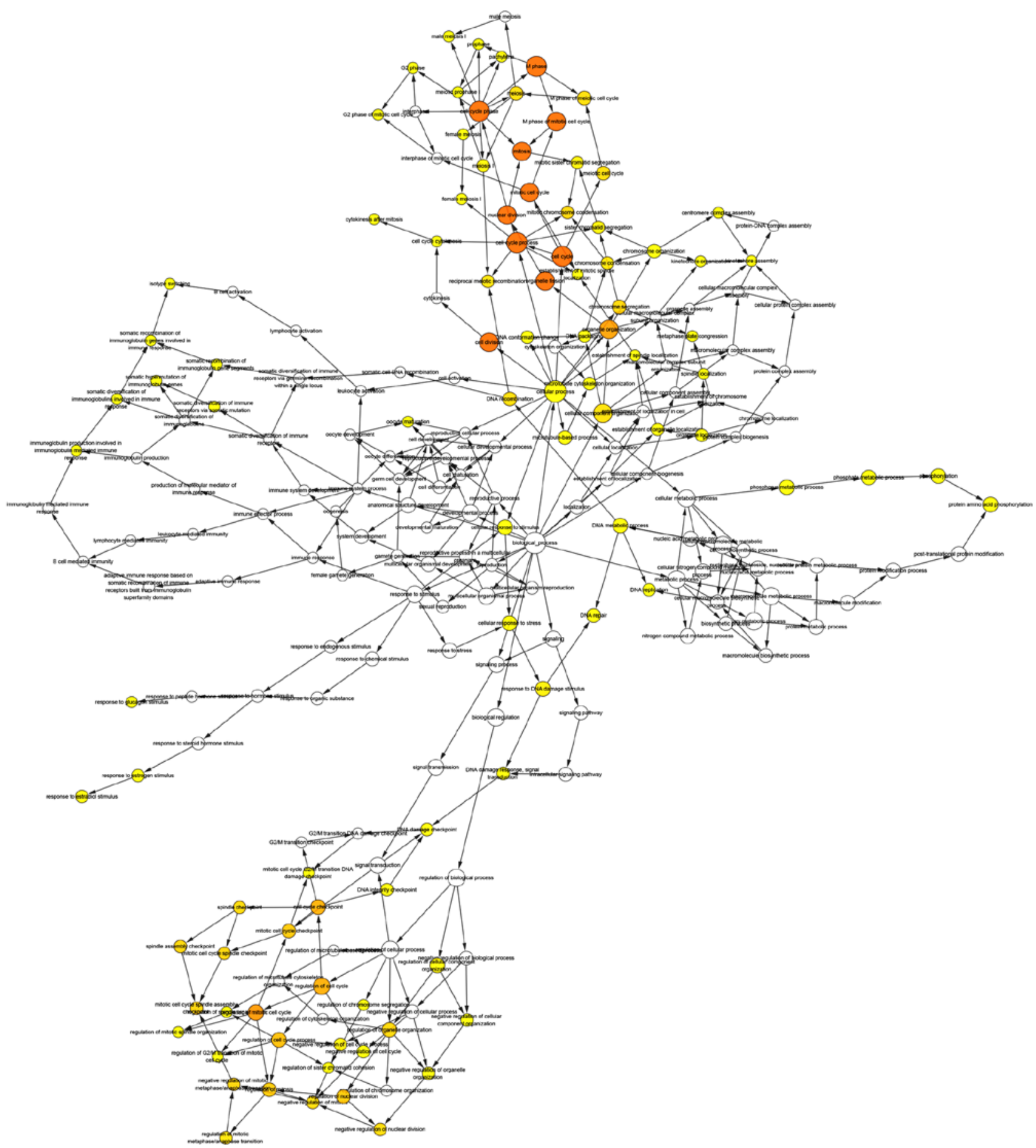

Figure 5. Biological process analysis of hub genes was constructed using the BiNGO (version 3.0.3) plugin in Cytoscape. The color depth of nodes refers to the corrected P-value of ontologies. The size of nodes refers to the numbers of genes that are involved in the ontologies.

that AURKA upregulation is restricted to specific subtypes and poorly differentiated tumors in NSCLC. Ma et al (31) revealed that CEP55 was upregulated in lung cancer cells and was associated with poor clinical outcomes in patients with lung cancer, and that it may serve as a prognostic biomarker for the disease.

The current study is only a preliminary report, and heterogeneous results due to the limitations of the source and quantity of samples may have occurred. Furthermore, statistical differences may not translate to the expected clinical significance. In order to be more representative, a specific pathological type of lung cancer was not selected in the current study. However, this may lead to poor specificity in lung cancer subtypes. The 16 hub genes identified revealed clinical significance in the validation of survival analysis. However, further validation in the subsequent basic and clinical trial studies is required. In addition to DEGs, further studies investigating differentially expressed microRNAs and their association with genes, particularly DEGs, are required.

In summary, the current study identified DEGs that may be involved in the carcinogenesis or progression of lung cancer. A total of 552 DEGs and 16 hub genes were identified, and these may serve as potential diagnostic biomarkers or therapeutic targets for lung cancer. The results suggested that data mining 

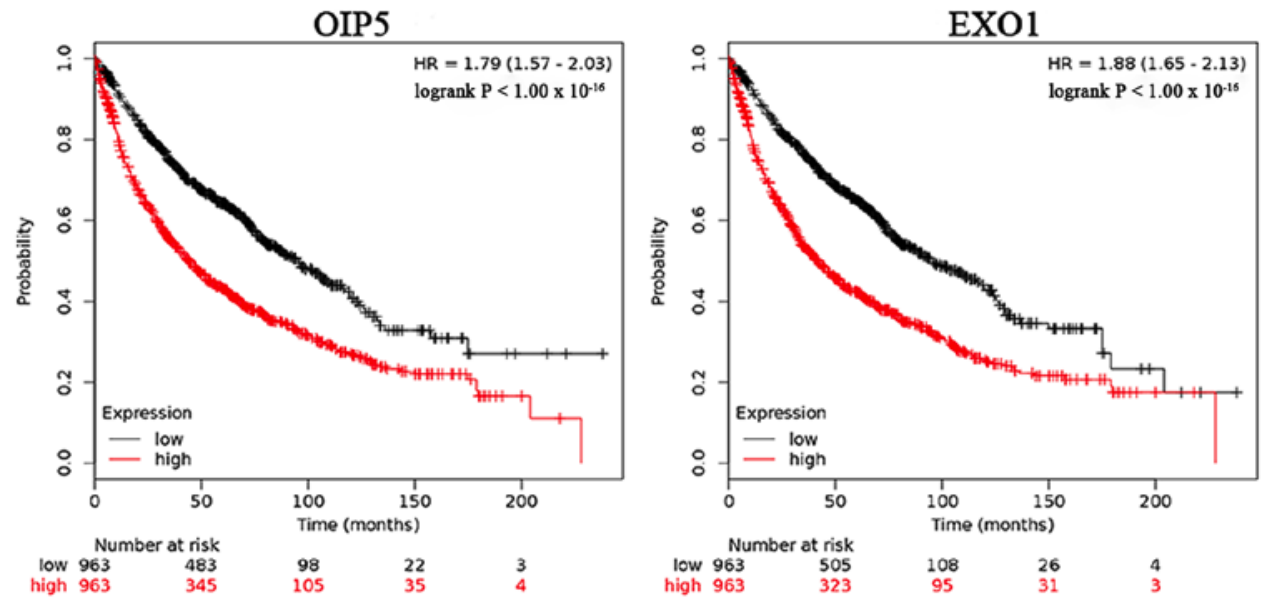

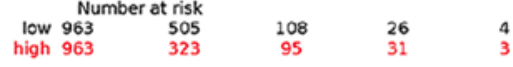
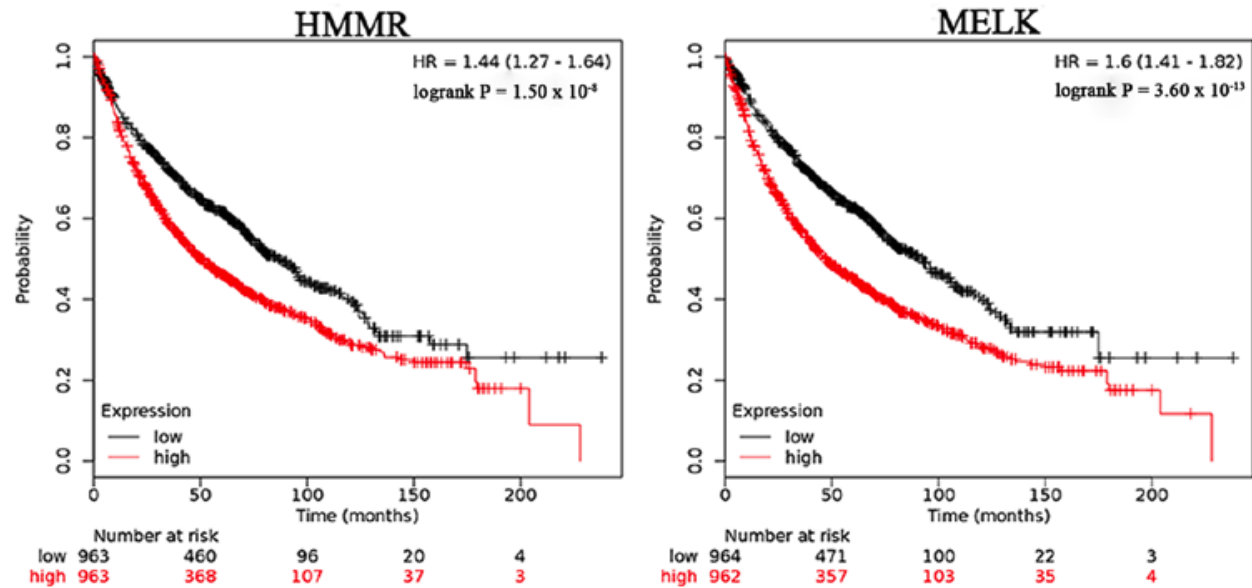

BUB1

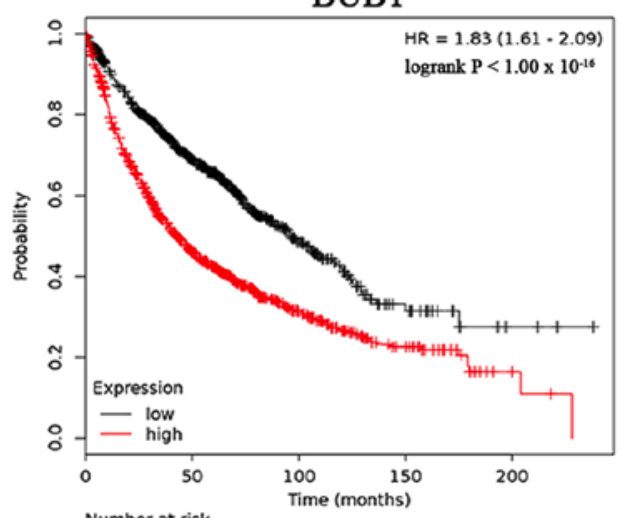

high $962 \quad 357 \quad 103 \quad 35 \quad 4$

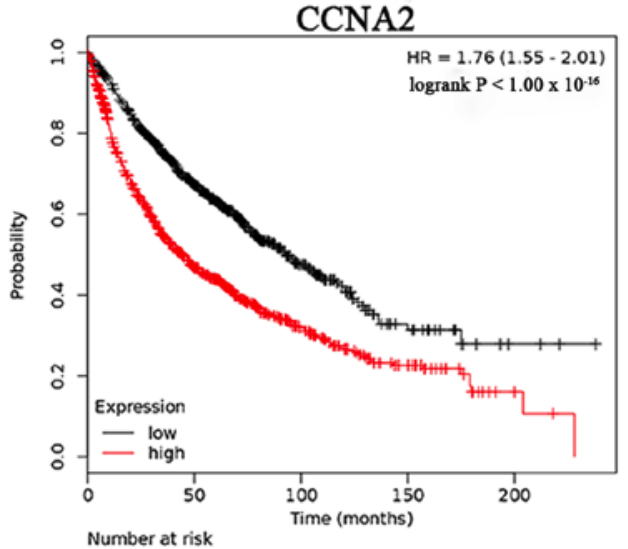

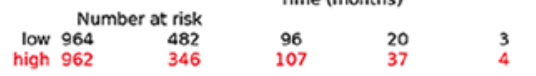

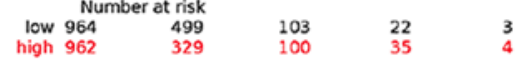
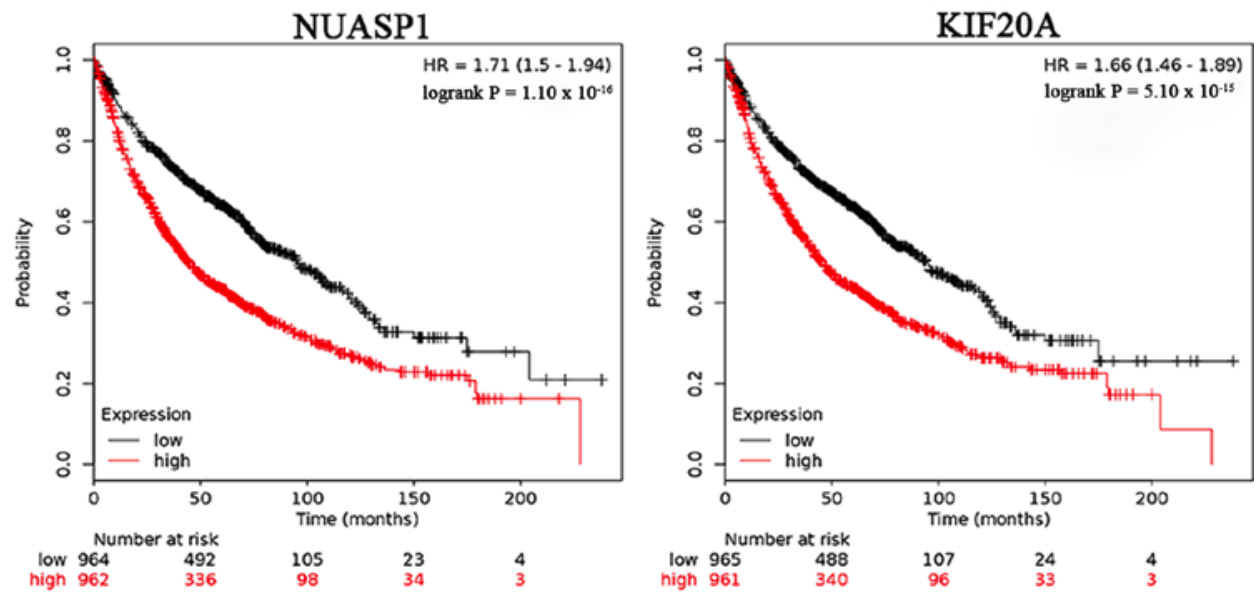

Figure 6. Overall survival analysis of 8 hub genes (OIP5, EXO1, HMMR, MELK, BUB1, CCNA2, NUSAP1 and KIF20A) was performed using the Kaplan-Meier plotter online platform. $\mathrm{P}<0.05$ was considered to indicate a statistically significant difference. HR, hazard ratio. 

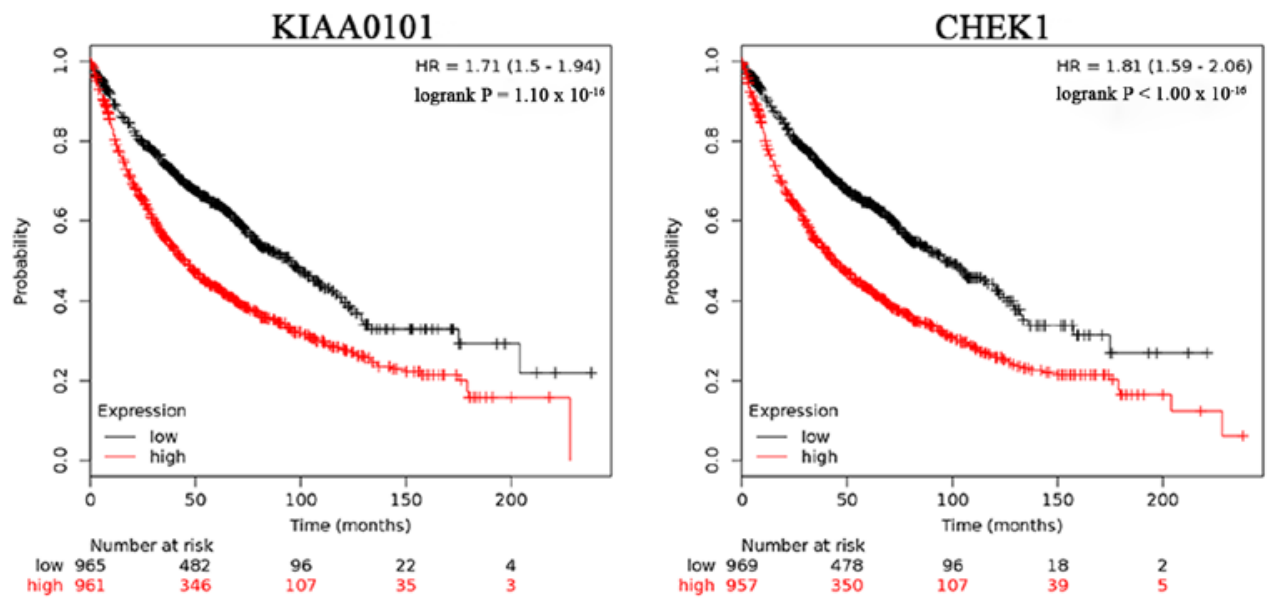

\begin{tabular}{ccccc}
\multicolumn{5}{c}{ Number at risk } \\
low 969 & 478 & 96 & 18 & 2 \\
high 957 & 350 & 107 & 39 & 5
\end{tabular}
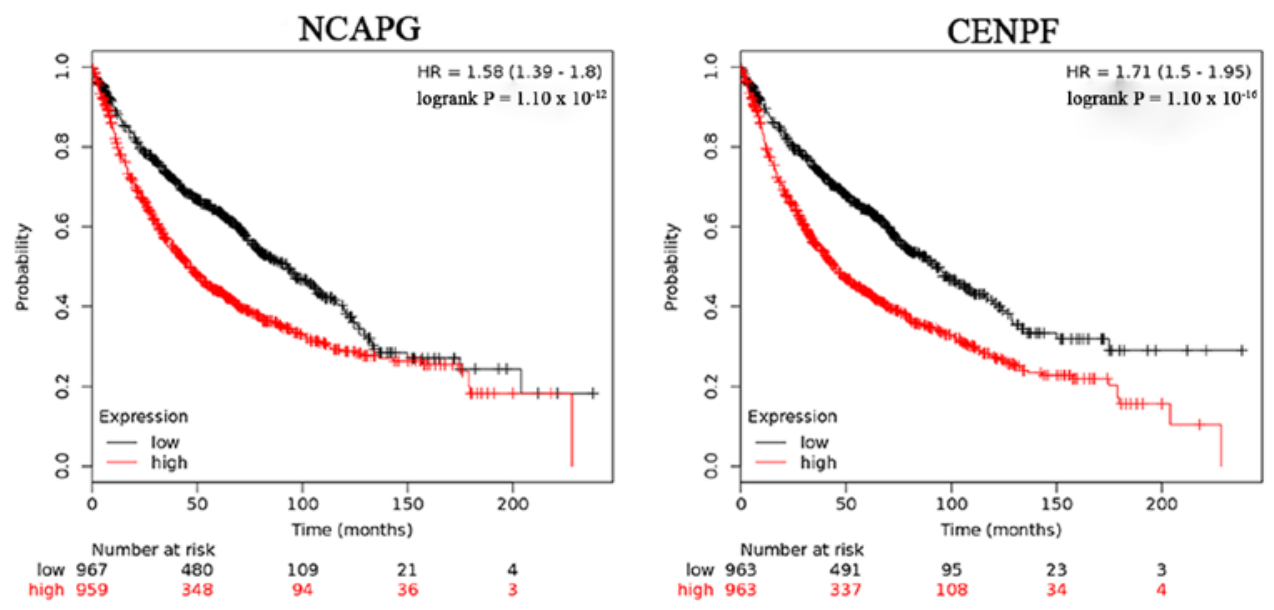

TRIP13

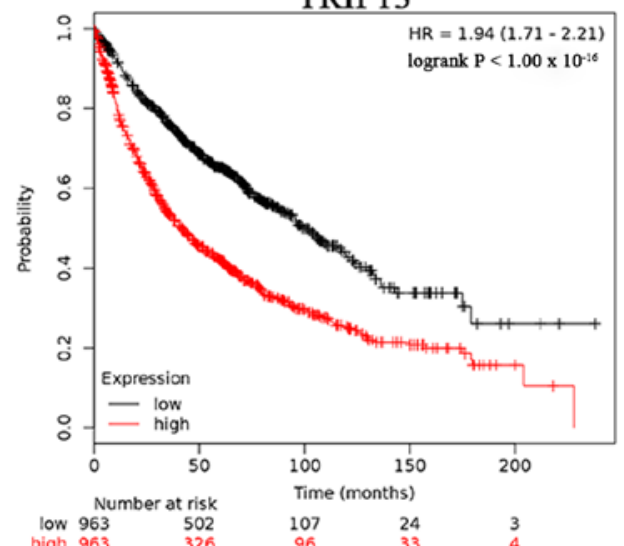

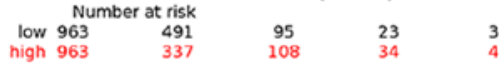
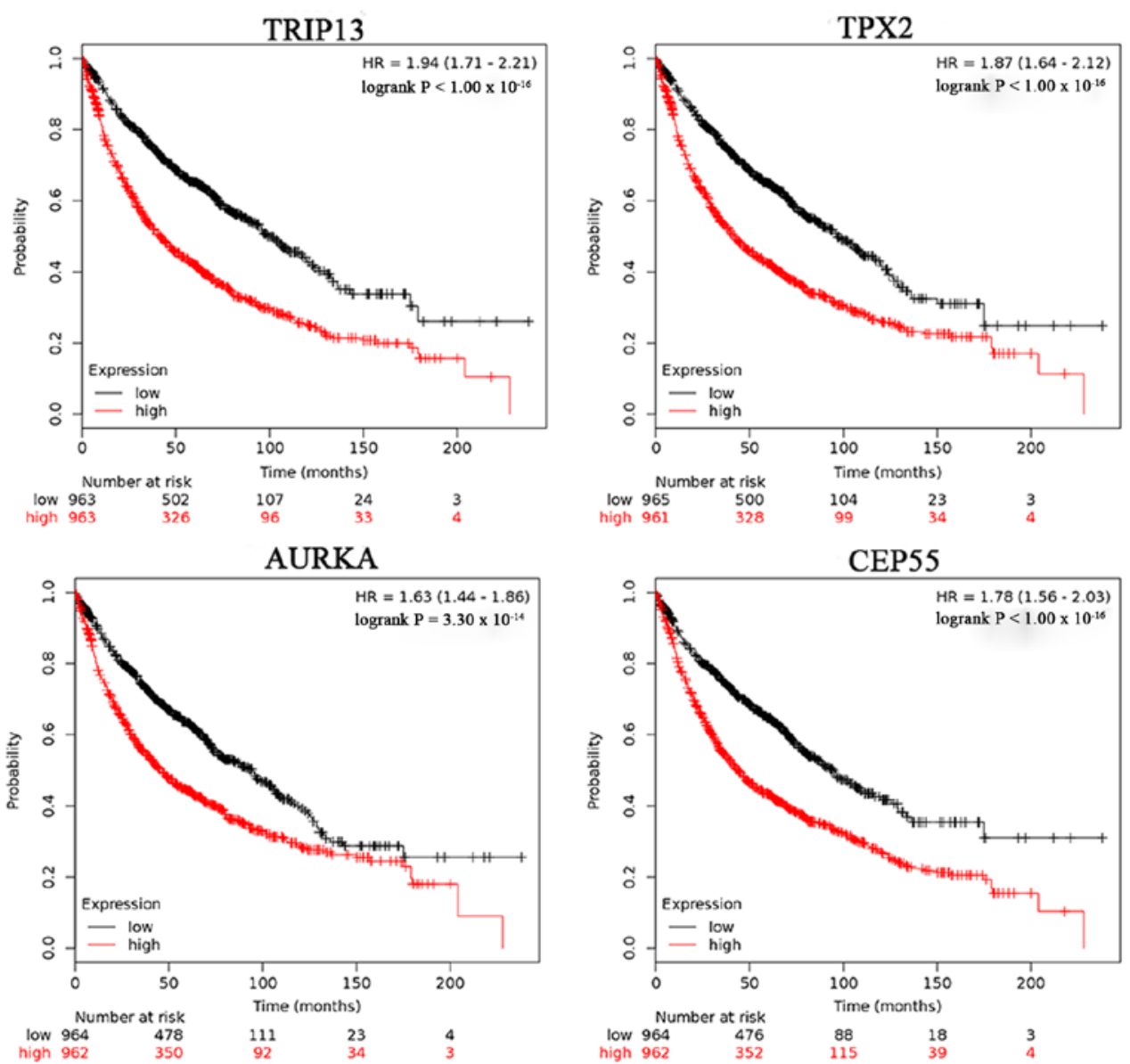

Figure 7. Overall survival analysis of eight hub genes (KIAA0101, CHEK1, NCAPG, CENPF, TRIP13, TPX2, AURKA and CEP55) were performed using the Kaplan-Meier plotter online platform. $\mathrm{P}<0.05$ was considered to indicate a statistically significant difference. HR, hazard ratio. 
Table II. Functional roles of 16 hub genes with $\geq 43$ degrees of interaction.

\begin{tabular}{|c|c|c|}
\hline Gene symbol & Gene name & Function \\
\hline OIP5 & Opa interacting protein 5 & $\begin{array}{l}\text { Required for recruitment of centromere protein A to centromeres and } \\
\text { normal chromosome segregation during mitosis. Expression of this } \\
\text { gene is upregulated in several types of cancer, making it a putative } \\
\text { therapeutic target. }\end{array}$ \\
\hline EXO1 & Exonuclease 1 & $\begin{array}{l}\text { Encodes a protein with } 5^{\prime} \text { to } 3^{\prime} \text { exonuclease activity, as well as an } \\
\text { RNase } \mathrm{H} \text { activity. }\end{array}$ \\
\hline KIAA0101 & PCNA clamp-associated factor & $\begin{array}{l}\text { PCNA-binding protein that acts as a regulator of DNA repair during } \\
\text { DNA replication. Also acts as a regulator of centrosome number. }\end{array}$ \\
\hline CHEK1 & Checkpoint kinase 1 & $\begin{array}{l}\text { Required for checkpoint-mediated cell cycle arrest in response to } \\
\text { DNA damage or the presence of unreplicated DNA. }\end{array}$ \\
\hline HMMR & Hyaluronan-mediated motility receptor & Encodes a protein involved in cell motility. \\
\hline MELK & $\begin{array}{l}\text { Maternal embryonic leucine zipper } \\
\text { kinase }\end{array}$ & $\begin{array}{l}\text { Serine/threonine-protein kinase involved in various processes, such } \\
\text { as cell cycle regulation, self-renewal of stem cells, apoptosis and } \\
\text { splicing regulation. }\end{array}$ \\
\hline NCAPG & $\begin{array}{l}\text { Non-SMC condensin I complex } \\
\text { subunit G }\end{array}$ & $\begin{array}{l}\text { Encodes a subunit of the condensin complex, which is responsible } \\
\text { for the condensation and stabilization of chromosomes during mitosis } \\
\text { and meiosis. }\end{array}$ \\
\hline CENPF & Centromere protein $\mathrm{F}$ & $\begin{array}{l}\text { Encodes a protein that associates with the centromere-kinetochore } \\
\text { complex. }\end{array}$ \\
\hline BUB1 & $\begin{array}{l}\text { BUB1 mitotic checkpoint } \\
\text { serine/threonine kinase }\end{array}$ & $\begin{array}{l}\text { Encodes a serine/threonine-protein kinase that serves a central role in } \\
\text { mitosis. Mutations in this gene have been associated with aneuploidy } \\
\text { and several forms of cancer. }\end{array}$ \\
\hline CCNA2 & Cyclin A2 & $\begin{array}{l}\text { Encodes a protein that binds and activates cyclin-dependent kinase } 2 \\
\text { and promotes transition through } \mathrm{G} 1 / \mathrm{S} \text { and } \mathrm{G} 2 / \mathrm{M} \text {. }\end{array}$ \\
\hline TRIP13 & $\begin{array}{l}\text { Thyroid hormone receptor } \\
\text { interactor } 13\end{array}$ & $\begin{array}{l}\text { Encodes a protein that interacts with thyroid hormone receptors, } \\
\text { which may serve a role in early-stage non-small cell lung cancer. }\end{array}$ \\
\hline TPX2 & Targeting protein for Xklp2 & $\begin{array}{l}\text { Spindle assembly factor required for normal assembly of mitotic } \\
\text { spindles. }\end{array}$ \\
\hline NUSAP1 & $\begin{array}{l}\text { Nucleolar and spindle-associated } \\
\text { protein } 1\end{array}$ & $\begin{array}{l}\text { Nucleolar-spindle-associated protein that serves a role in spindle } \\
\text { microtubule organization. }\end{array}$ \\
\hline KIF20A & Kinesin family member $20 \mathrm{~A}$ & $\begin{array}{l}\text { Mitotic kinesin required for chromosome passenger complex-mediated } \\
\text { cytokinesis. }\end{array}$ \\
\hline AURKA & Aurora kinase $\mathrm{A}$ & $\begin{array}{l}\text { Encodes a cell cycle-regulated kinase involved in microtubule } \\
\text { formation and/or stabilization at the spindle pole during chromosome } \\
\text { segregation. }\end{array}$ \\
\hline CEP55 & Centrosomal protein 55 & Serves a role in mitotic exit and cytokinesis. \\
\hline
\end{tabular}

and integration may be a promising tool for the identification of biomarkers in malignant tumors. As tumor biomarkers only have meaning if they are integrated with clinical data, further experiments should be conducted to verify the results obtained in the current study.

\section{Acknowledgements}

Not applicable.

\section{Funding}

No funding was received.

\section{Availability of data and materials}

The datasets generated and/or analyzed during the current study are available in the GEO repository (www.ncbi.nlm.nih. gov/geo).

\section{Authors' contributions}

ZHL and BES designed the overall research. ZL, JL and FZ collected the data. ZHL, MXS, ZQT, ZL and BES contributed to data analysis and visualization. JL and FZ drafted and revised the manuscript. All authors approved the final version of the manuscript. 


\section{Ethics approval and consent to participate}

Not applicable.

\section{Patient consent for publication}

Not applicable.

\section{Competing interests}

The authors declare that they have no competing interests.

\section{References}

1. Bray F, Ferlay J, Soerjomataram I, Siegel RL, Torre LA and Jemal A: Global cancer statistics 2018: GLOBOCAN estimates of incidence and mortality worldwide for 36 cancers in 185 countries. CA Cancer J Clin 68: 394-424, 2018.

2. Nana-Sinkam SP and Powell CA: Molecular biology of lung cancer: Diagnosis and management of lung cancer, 3rd ed American College of Chest Physicians evidence-based clinical practice guidelines. Chest 143: e30S-e39S, 2013.

3. Solomon BJ, Mok T, Kim DW, Wu YL, Nakagawa K, Mekhail T, Felip E, Cappuzzo F, Paolini J, Usari T, et al: First-line crizotinib versus chemotherapy in ALK-positive lung cancer. N Engl J Med 371: 2167-2177, 2014.

4. Mok TS: Personalized medicine in lung cancer: What we need to know. Nat Rev Clin Oncol 8: 661-668, 2011.

5. Sharma SV, Bell DW, Settleman J and Haber DA: Epidermal growth factor receptor mutations in lung cancer. Nat Rev Cancer 7: 169-181, 2007.

6. Shao Y, Liang B, Long F and Jiang SJ: Diagnostic microRNA biomarker discovery for non-small-cell lung cancer adenocarcinoma by integrative bioinformatics analysis. Biomed Res Int 2017: 2563085, 2017.

7. Wang LQ, Zhao LH and Qiao YZ: Identification of potential therapeutic targets for lung cancer by bioinformatics analysis. Mol Med Rep 13: 1975-1982, 2016.

8. Edgar R, Domrachev M and Lash AE: Gene Expression Omnibus: NCBI gene expression and hybridization array data repository. Nucleic Acids Res 30: 207-210, 2002.

9. Mitchell KA, Zingone A, Toulabi L, Boeckelman J and Ryan BM: Comparative transcriptome profiling reveals coding and noncoding RNA differences in NSCLC from African Americans and European Americans. Clin Cancer Res 23: 7412-7425, 2017.

10. Marwitz S, Depner S, Dvornikov D, Merkle R, Szczygieł M, Müller-Decker $\mathrm{K}$, Lucarelli $\mathrm{P}$, Wäsch $\mathrm{M}$, Mairbäurl $\mathrm{H}$, Rabe KF, et al: Downregulation of the TGF $\beta$ pseudoreceptor BAMBI in non-small cell lung cancer enhances TGF $\beta$ signaling and invasion. Cancer Res 76: 3785-3801, 2016

11. Barrett T, Wilhite SE, Ledoux P, Evangelista C, Kim IF, Tomashevsky M, Marshall KA, Phillippy KH, Sherman PM, Holko M, et al: NCBI GEO: Archive for functional genomics data sets-update. Nucleic Acids Res 41: D991-D995, 2013.

12. Huang DW, Sherman BT, Tan Q, Collins JR, Alvord WG, Roayaei J, Stephens R, Baseler MW, Lane HC and Lempicki RA: The DAVID Gene Functional Classification Tool: A novel biological module-centric algorithm to functionally analyze large gene lists. Genome Biol 8: R183, 2007.

13. Kanehisa M: The KEGG database. Novartis Found Symp 247: 91-103, 2002.

14. Szklarczyk D, Franceschini A, Wyder S, Forslund K, Heller D, Huerta-Cepas J, Simonovic M, Roth A, Santos A, Tsafou KP, et al: STRING v10: Protein-protein interaction networks, integrated over the tree of life. Nucleic Acids Res 43: D447-D452, 2015.

15. Shannon P, Markiel A, Ozier O, Baliga NS, Wang JT, Ramage D, Amin N, Schwikowski B and Ideker T: Cytoscape: A software environment for integrated models of biomolecular interaction networks. Genome Res 13: 2498-2504, 2003.

16. Bader GD and Hogue CW: An automated method for finding molecular complexes in large protein interaction networks. BMC Bioinformatics 4: 2, 2003.
17. Cerami E, Gao J, Dogrusoz U, Gross BE, Sumer SO, Aksoy BA, Jacobsen A, Byrne CJ, Heuer ML, Larsson E, et al: The cBio cancer genomics portal: An open platform for exploring multidimensional cancer genomics data. Cancer Discov 2: 401-404, 2012.

18. Maere S, Heymans K and Kuiper M: BiNGO: A Cytoscape plugin to assess overrepresentation of gene ontology categories in biological networks. Bioinformatics 21: 3448-3449, 2005.

19. Nagy Á, Lánczky A, Menyhárt $\mathrm{O}$ and Győrffy B: Validation of miRNA prognostic power in hepatocellular carcinoma using expression data of independent datasets. Sci Rep 8: 9227, 2018.

20. Li T, Gao X, Han L, Yu J and Li H: Identification of hub genes with prognostic values in gastric cancer by bioinformatics analysis. World J Surg Oncol 16: 114, 2018.

21. Bunn PA Jr: Karnofsky award 2016: A lung cancer journey, 1973 to 2016. J Clin Oncol 35: 243-252, 2017.

22. Hirsch FR, Scagliotti GV, Mulshine JL, Kwon R, Curran WJ Jr, Wu YL and Paz-Ares L: Lung cancer: Current therapies and new targeted treatments. Lancet 389: 299-311, 2017.

23. Mendell JT: MicroRNAs: Critical regulators of development, cellular physiology and malignancy. Cell Cycle 4: 1179-1184, 2005.

24. Xiao Y, Feng M, Ran H, Han X and Li X: Identification of key differentially expressed genes associated with non-small cell lung cancer by bioinformatics analyses. Mol Med Rep 17: 6379-6386, 2018.

25. Wen P, Chidanguro T, Shi Z, Gu H, Wang N, Wang T, Li Y and Gao J: Identification of candidate biomarkers and pathways associated with SCLC by bioinformatics analysis. Mol Med Rep 18 1538-1550, 2018

26. Tang Q, Zhang H, Kong M, Mao X and Cao X: Hub genes and key pathways of non-small lung cancer identified using bioinformatics. Oncol Lett 16: 2344-2354, 2018.

27. Kato T, Daigo Y, Aragaki M, Ishikawa K, Sato M and Kaji M: Overexpression of KIAA0101 predicts poor prognosis in primary lung cancer patients. Lung Cancer 75: 110-118, 2012.

28. Man Y, Cao J, Jin S, Xu G, Pan B, Shang L, Che D, Yu Q and Yu Y: Newly identified biomarkers for detecting circulating tumor cells in lung adenocarcinoma. Tohoku J Exp Med 234: 29-40, 2014.

29. Kim DH, Park SE, Kim M, Ji YI, Kang MY, Jung EH, Ko E, Kim Y, Kim S, Shim YM and Park J: A functional single nucleotide polymorphism at the promoter region of cyclin A2 is associated with increased risk of colon, liver, and lung cancers. Cancer 117: 4080-4091, 2011

30. Li W, Zhang G, Li X, Wang X, Li Q, Hong L, Shen Y, Zhao C, Gong X, Chen Y and Zhou J: Thyroid hormone receptor interactor 13 (TRIP13) overexpression associated with tumor progression and poor prognosis in lung adenocarcinoma. Biochem Biophys Res Commun 499: 416-424, 2018.

31. Ma XP, Zhang W, Wu BQ and Qin J: Correlations between mRNA levels of centrosomal protein 55 (CEP55) and clinical features of patients with lung cancer. Med Sci Monit 24: 3093-3097, 2018.

32. Chiang IT, Wang WS, Liu HC, Yang ST, Tang NY and Chung JG: Curcumin alters gene expression-associated DNA damage, cell cycle, cell survival and cell migration and invasion in NCI-H460 human lung cancer cells in vitro. Oncol Rep 34: 1853-1874, 2015

33. Wan J, Zou S, Hu M, Zhu R, Xu J, Jiao Y and Fan S: Thoc1 inhibits cell growth via induction of cell cycle arrest and apoptosis in lung cancer cells. Mol Med Rep 9: 2321-2327, 2014.

34. Wen J, Fu J, Zhang W and Guo M: Genetic and epigenetic changes in lung carcinoma and their clinical implications. Mod Pathol 24: 932-943, 2011.

35. Chun HK, Chung KS, Kim HC, Kang JE, Kang MA, Kim JT, Choi EH, Jung KE, Kim MH, Song EY, et al: OIP5 is a highly expressed potential therapeutic target for colorectal and gastric cancers. BMB Rep 43: 349-354, 2010.

36. Gong M, Xu Y, Dong W, Guo G, Ni W, Wang Y, Wang Y and An R: Expression of Opa interacting protein 5 (OIP5) is associated with tumor stage and prognosis of clear cell renal cell carcinoma. Acta Histochem 115: 810-815, 2013.

37. Tang J, Tang S, Liu J, Wu Q, Wan L and Xu Q: Genetic risk of lung cancer associated with a single nucleotide polymorphism from EXO1: A meta analysis. Int J Clin Exp Med 8: 11132-11138, 2015.

38. Hsu NY, Wang HC, Wang CH, Chiu CF, Tseng HC, Liang SY, Tsai CW, Lin CC and Bau DT: Lung cancer susceptibility and genetic polymorphisms of Exol gene in Taiwan. Anticancer Res 29: 725-730, 2009. 
39. Zhu K, Diao D, Dang C, Shi L, Wang J, Yan R, Yuan D and Li K: Elevated KIAA0101 expression is a marker of recurrence in human gastric cancer. Cancer Sci 104: 353-359, 2013.

40. Fan S, Li X, Tie L, Pan Y and Li X: KIAA0101 is associated with human renal cell carcinoma proliferation and migration induced by erythropoietin. Oncotarget 7: 13520-13537, 2016.

41. Liu B, Qu J, Xu F, Guo Y, Wang Y, Yu H and Qian B: MiR-195 suppresses non-small cell lung cancer by targeting CHEK1. Oncotarget 6: 9445-9456, 2015.

42. Inoue H, Kato T, Olugbile S, Tamura K, Chung S, Miyamoto T, Matsuo Y, Salgia R, Nakamura Y and Park JH: Effective growth-suppressive activity of maternal embryonic leucine-zipper kinase (MELK) inhibitor against small cell lung cancer. Oncotarget 7: 13621-13633, 2016.

43. Pitner MK, Taliaferro JM, Dalby KN and Bartholomeusz C: MELK: A potential novel therapeutic target for TNBC and other aggressive malignancies. Expert Opin Ther Targets 21: 849-859, 2017.

44. Zhang Q, Su R, Shan C, Gao C and Wu P: Non-SMC condensin I complex, subunit G (NCAPG) is a novel mitotic gene required for hepatocellular cancer cell proliferation and migration. Oncol Res 26: 269-276, 2018.

45. Kim HE, Kim DG, Lee KJ, Son JG, Song MY, Park YM, Kim JJ, Cho SW, Chi SG, Cheong HS, et al: Frequent amplification of CENPF, GMNN and CDK13 genes in hepatocellular carcinomas. PLoS One 7: e43223, 2012.

46. Aytes A, Mitrofanova A, Lefebvre C, Alvarez MJ, Castillo-Martin M, Zheng T, Eastham JA, Gopalan A, Pienta KJ, Shen MM, et al: Cross-species regulatory network analysis identifies a synergistic interaction between FOXM1 and CENPF that drives prostate cancer malignancy. Cancer Cell 25: 638-651, 2014.

47. Takagi K, Miki Y, Shibahara Y, Nakamura Y, Ebata A, Watanabe M, Ishida T, Sasano H and Suzuki T: BUB1 immunolocalization in breast carcinoma: Its nuclear localization as a potent prognostic factor of the patients. Horm Cancer 4: 92-102, 2013.

48. Li L, Xu DB, Zhao XL and Hao TY: Combination analysis of Bub1 and Mad2 expression in endometrial cancer: Act as a prognostic factor in endometrial cancer. Arch Gynecol Obstet 288: $155-165,2013$.
49. Haruki N, Saito H, Harano T, Nomoto S, Takahashi T, Osada H, Fujii Y and Takahashi T: Molecular analysis of the mitotic checkpoint genes BUB1, BUBR1 and BUB3 in human lung cancers. Cancer Lett 162: 201-205, 2001.

50. Yang J, Gao F, Xu X, Wang Y and Zhu S: Targeting protein for Xenopus kinesin-like protein 2 knockdown enhances radiation sensitivity of human lung squamous carcinoma cell. Clin Exp Pharmacol Physiol 44: 1060-1068, 2017.

51. Schneider MA, Christopoulos P, Muley T, Warth A, Klingmueller U, Thomas M, Herth FJ, Dienemann H, Mueller NS, Theis F and Meister M: AURKA, DLGAP5, TPX2, KIF11 and CKAP5: Five specific mitosis-associated genes correlate with poor prognosis for non-small cell lung cancer patients. Int J Oncol 50: 365-372, 2017.

52. Zhang M, Yang D, Liu X, Liu Y, Liang J, He H, Zhong K, Lin L, Tao G, Zhang C and Zhou J: Expression of Nusap1 in the surgical margins of hepatocellular carcinoma and its association with early recurrence. Nan Fang Yi Ke Da Xue Xue Bao 33: 937-938, inside back cover, 2013 (In Chinese).

53. Gordon CA, Gulzar ZG and Brooks JD: NUSAP1 expression is upregulated by loss of RB1 in prostate cancer cells. Prostate 75: 517-526, 2015.

54. Zhao X, Zhou LL, Li X, Ni J, Chen P, Ma R, Wu J and Feng J: Overexpression of KIF20A confers malignant phenotype of lung adenocarcinoma by promoting cell proliferation and inhibiting apoptosis. Cancer Med 7: 4678-4689, 2018.

55. Ma ZL, Zhang BJ, Wang DT, Li X, Wei JL, Zhao BT, Jin Y, Li YL and Jin YX: Tanshinones suppress AURKA through up-regulation of miR-32 expression in non-small cell lung cancer. Oncotarget 6: 20111-20120, 2015

56. Lo Iacono M, Monica V, Saviozzi S, Ceppi P, Bracco E, Papotti M and Scagliotti GV: Aurora Kinase A expression is associated with lung cancer histological-subtypes and with tumor de-differentiation. J Transl Med 9: 100, 2011.

This work is licensed under a Creative Commons Attribution-NonCommercial-NoDerivatives 4.0 International (CC BY-NC-ND 4.0) License. 